\title{
Infections Caused by RSV Among Children and Adults During Two Epidemic Seasons
}

\author{
KATARZYNA PANCER ${ }^{* 1}$, AGNIESZKA CIĄĆKA ${ }^{1}$, WŁODZIMIERZ GUT¹ ${ }^{1}$ BOŻENA LIPKA², \\ JUSTYNA MIERZEJEWSKA ${ }^{3}$, BOGUMIŁA MILEWSKA-BOBULA², ANNA SMORCZEWSKA-KILJAN², \\ KARINA JAHNZ-RÓŻYK ${ }^{3}$, DANUTA DZIERŻANOWSKA², KAZIMIERZ MADALIŃSKI ${ }^{1}$ \\ and BOGUMIŁA LITWIŃSKA ${ }^{1}$
}
${ }^{1}$ Department of Virology, National Institute of Public Heath - National Institute of Hygiene, Warsaw, Poland
${ }^{2}$ The Children's Memorial Health Institute, Warsaw, Poland
${ }^{3}$ Department of Immunology and Clinical Allergology, Military Institute of Medicine, Warsaw, Poland

Received 2 June 2011, revised 15 July 2011, accepted 16 July 2011

\begin{abstract}
Respiratory Syncytial Virus (RSV) is one of the most common causes of lower respiratory tract infections in young children, immunocompromised patients (children and adults), patients with chronic respiratory diseases and elderly people. Reinfections occur throughout the life, but the severity of disease decreased with subsequent infection. The aim of this study was to analyze the frequency of RSV infections in two selected subpopulations: young children (below 5 y.) and adults with chronic respiratory diseases (25-87 y.). Nasopharyngeal swabs (334) collected from October 2008 to March 2010 were examined. The presence of RSV genome was determined by RT-PCR and the presence of RSV antigen by quick immunochromatographic test. Positive results of RT-PCR were found in $45.2 \%$ of all swabs: $48.6 \%$ samples in 2008 ; $41.5 \%$ in 2009 ; $50.8 \%$ in 2010. The highest frequency of RSV-positive samples was in fall-winter months, but differences in RSV epidemic seasons were found. In the first season (2008-2009) an increased number of RSV infections was observed from November 2008, but in the second season - from January 2010. Generally, the frequency of RSV-positive RT-PCR among children was 53\%, among adults $25 \%$. The highest difference was observed in the first three-month period of 2010. RT-PCR positive samples were found in $68.5 \%$ of children and $5.9 \%$ of adults. However, the RSV antigen was found in $44.4 \%$ of samples collected from adults in this period. Our results indicate that the contribution of RSV infections during epidemic season of respiratory tract infections in Poland was really high among children and adults.
\end{abstract}

Ke y words: RSV, epidemic seasons, high risk groups

\section{Introduction}

Respiratory syncytial virus (RSV) is a member of Paramyxoviridae family, structured with ss-RNA of negative polarity, and lipid bilayer envelope that is derived from membrane of the host cell. On the surface of the envelope there are two glycoproteins: fusion protein (F) and G protein (G) (Lamb and Parks, 2007).

RSV is the most common etiological agent of viral lower respiratory tract infections among infants and young children in the world. RSV is the most frequent cause of bronchiolitis and pneumonia in hospitalized children below 9 months of age (Iwane et al., 2004). It has been counted that over one-third of all infants below 1 year old admitted to the hospital due to lower respiratory tract infection were infected by RSV. Overall, 4-5 millions of young children $(<4$ y.) per year in USA acquire an RSV infection and among them $\sim 125000$ are hospitalized due to this infection and $~ 450$ die (Iwane et al., 2004; Black, 2003; Krilov, http://emedicine.medscape.co./article/971488). It might be estimated that 3-9 per 1000 children below $1 \mathrm{y}$. were hospitalized because of severe RSV infections. Probably, every child in early childhood got at least one infection caused by RSV but may have been asymptomatic or with moderate symptoms. In Thailand, 417.1/100 000 incidences of pneumonia per year were connected with RSV infections in children below $5 \mathrm{y}$. (Olsen et al., 2010). Meta-analysis performed by Nair et al. (2010) indicated, that 33.8 million of new episodes of RSV infections were occurred worldwide in children $<5 \mathrm{y}$. in 2005. Among them, 3.4 million cases were associated with acute lower respiratory infections (ALRI) which required hospitalization. The authors also estimated that 66 000-199000 children (<5 y.) died from ALRI associated with RSV in 2005. The majority of deaths

* Corresponding author: K. Pancer, National Institute of Public Health-National Institute of Hygiene, Chocimska 24, 00-791 Warsaw, Poland; phone: +48 22 5421308; fax: +48 22 5421385; e-mail:kpancer@pzh.gov.pl 
were in developing countries (estimated 99\%) (Nair et al., 2010).

RSV was not found as a potential agent of severe infections in adults until 1970s, when outbreaks of RSV infections in long-term care facilities were recognized (Falsey et al., 1992). Next studies showed that RSV should be treated as an important cause of illness of elderly people (+65y.) especially in community-dwelling (nursing houses, hospitals etc.) (Falsey et al., 2005).

The mortality rate due to RSV infections is dependent on the age of patient and presence of risk factors. Among younger children hospitalized with RSV infection - without additional risk factors- the mortality rate is less than $1 \%$. High-risk mortality rate occurs among:

1. infants with chronic lung disease (e.g. bronchopulmonary dysplasia), congenital heart disease, prematurity, low birth weight, artificial nutrition - 3-5\% (Black, 2003; Krilov, http://emedicine.medscape.co./ article/971488; Sullender, 2000)

2. immunocompromised patients, elderly people with underlying disease $-8 \%$ of hospitalized (Falsey et al., 1992).

Data regarding RSV infections in Poland are rather modest or/and incomplete (Belino-Studzińska and Pancer, 2008; Światły, 2001; Tranda et al., 2000). The majority of publications on RSV infection in Poland were based on results of serological examinations (Tranda et al., 2000; Łuczak et al., 2003). The problems of serological diagnosis of RSV infection were discussed previously (Pancer et al., 2010b). Briefly the problems of interpretation of specific to RSV IgM or IgG level determinations, especially among the youngest children ( $<6$ months), may be connected with necessity of cutoff value correction. Moreover the most of researches in Poland were focused only on one group of high risk of RSV infection - young children.

The aim of this study was to analyze the frequency of RSV infections in two selected high risk groups: young children and adults with chronic respiratory tract diseases.

\section{Experimental}

Material and Methods

Clinical specimens. Nasopharyngeal swabs from patients with viral respiratory tract infection (lower respiratory tract infection or upper respiratory tract infection or both) were collected and stored at $-70^{\circ} \mathrm{C}$. Selection of patients, based on clinical symptoms of infection, was done by clinicians. All patients or their parents were informed about the project (subject, scientific targets, limits) and they agreed to participate in this study (according to decision of The Bioethics Committee in the Military Institute of Medicine, $n^{\circ} 87 / W I M / 2006$, and decision of The Bioethics Committee in The Children's Memorial Health Institute, $\left.n^{\circ} 100 / \mathrm{KBE} / 2007\right)$.

The samples were collected in the period from October 2008 to March 2010. In total 352 nasopharyngeal swabs were collected, among them - 254 from children and 98 - from adults. Eighteen samples were excluded because of use for nasopharyngeal specimen collection out of the procedure. Finally, 334 samples were examined (228 from children and 96 from adults).

There were two groups of high risk of RSV infection formed:

1. Young children - aged from 1 day of life to $5 y$. with acute viral respiratory infection hospitalized in the Children's Memorial Health Institute. Sixty percent of the children were $\leq 6$ months old. The majority of young patients (84\%) were admitted to the hospital because of acute viral respiratory infections, in $16 \%$ of children viral respiratory infection was recognized during hospitalization.

2. Adult patients with chronic respiratory diseases - aged from $27 \mathrm{y}$. to $87 \mathrm{y}$., half of them (54\%) were $\geq 60 \mathrm{y}$. The samples were collected from the outpatients of the Immunology and Clinical Allergology Department, Military Institute of Medicine. They visited their doctor because of acute respiratory infection or exacerbation of the symptoms of respiratory tract disease.

Classical RT-PCR. RNA was isolated from samples using QIAamp Viral RNA Mini kit (Qiagen) and stored at $-70^{\circ} \mathrm{C}$. Classical nested RT-PCR (Pancer et al., 2010a; Roca et al., 2001) for detecting viral RNA was performed in all clinical specimens (nasopharyngeal swabs). Briefly, nested RT-PCR reaction was done using Access RT-PCR System kit (Promega), at the C1000 Thermal Cycler (Biorad). The primers and conditions of reactions for the first and second step of nested PCR were described previously (Roca et al., 2001).

Detection of RSV antigen. The immunochromatografic test for qualitative detection of RSV antigen (Biotrin RSV Solo Assay, Ireland) was used for examination of 125/334 samples (collected from 57 children and 68 adults).

Statistical analysis. The Statgraphic Centurion v.XV was used for analysis of correlation between obtained results and data of age, gender, onset date.

\section{Results}

In total, the genome of RSV was detected in 151 swab samples (45.2\%). The frequency of detected RSV RNA was higher among children (53\%) than among adults (25\%). Genome of RSV was found in $50 \%$ of samples obtained from children in 2008; $43.8 \%$ in 2009 and in $68.5 \%$ in the first quarter of 2010 . Among adults posi- 


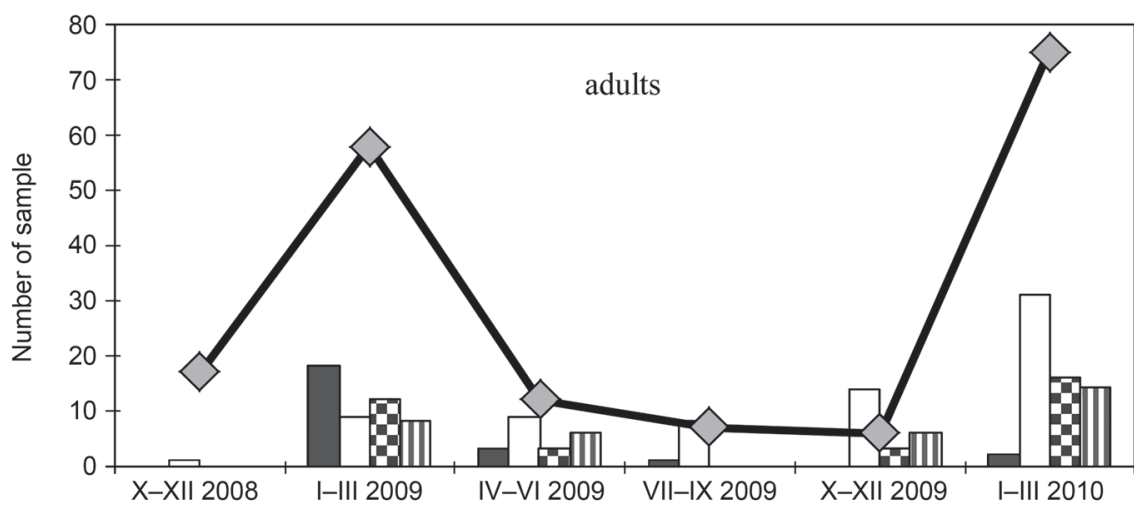

Quarters

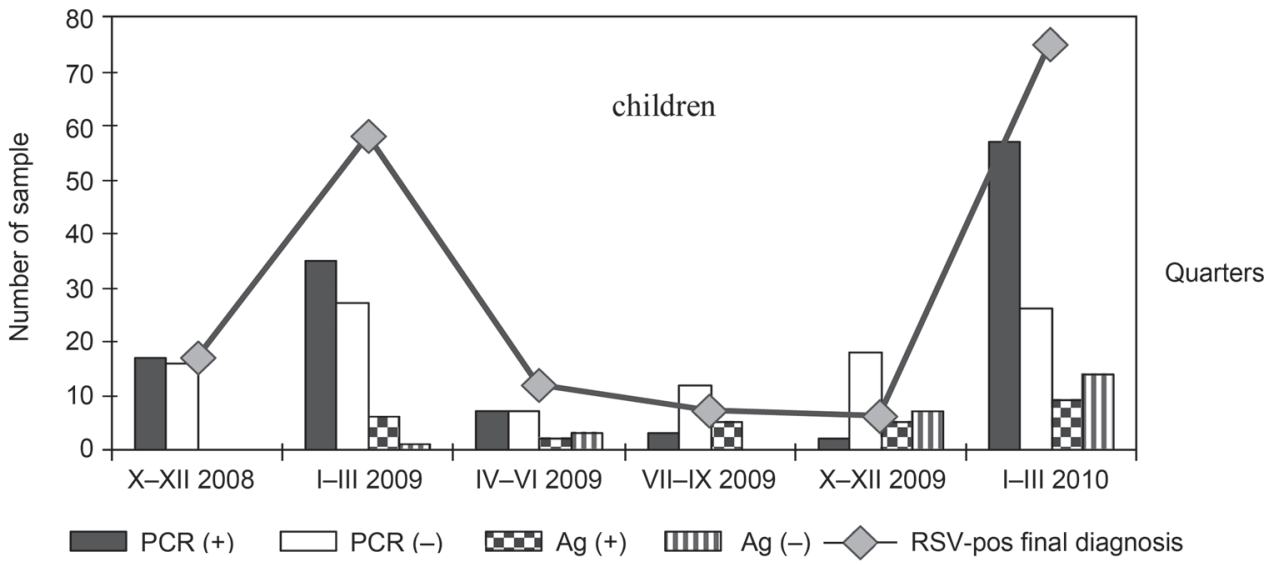

Fig. 1. Determination of RSV genome (PCR) and RSV antigen (Ag) in children and adults by quarter of onset in comparison to final diagnosis of RSV infection (RSV-pos).

tive PCR samples were determined in $0 \% ; 36.7 \%$ and $5.9 \%$ respectively, but only few samples collected from adults were examined in 2008.

Detection of RSV antigen by immunochromatografic test (RSV Ag) in selected 125 swab samples (57 children, 68 adults) was performed. Among 125 samples 64 were positive $(51.2 \%)$ in total. The frequency of RSV Ag positive samples in children and adults were similar: 54.4\% and 50\%. Among 64 examined samples 36 (56\%) were RSV Ag positive in 2009 and $28 / 59(47.5 \%)$ in the first 3 months of 2010.

The final laboratory diagnosis of RSV infection was posed on the base of both results of examinations: RT-PCR and RSV Ag. Among 334 patients 182 cases of RSV infection (54.5\%) were confirmed by RNA PCR and/or presence of RSV antigen, among them 138 children and 44 adults. The relation of results by RT-PCR or RSV Ag to final RSV diagnosis are presented in figure 1. As it was shown, the highest percentage of RSV(+) diagnosis was obtained by RT-PCR method.

The analysis of gender of patients and detection of RSV genome/antigen showed lack of influence of sex on the RSV infection in all examined people $(\mathrm{Po}=0.1434)$, as well as in adults and children (respectively $\mathrm{Po}=0.2076$ and $\mathrm{Po}=0.2762$ ). RSV infection was found in $67 \%$ of examined boys and $57 \%$ of girls and $53 \%$ of examined men and $39 \%$ women.
An analysis of age of RSV infected patients was also performed. There was no correlation between the age of patients and detection of RSV infection $(\mathrm{Po}=0.0903)$, also among children $(\mathrm{Po}=0.1486)$ and adults $(\mathrm{Po}=0.2889)$. The highest frequency of RSV positive samples (65.0\%) was found among the youngest children ( $\leq 6$ months). In this group the diagnosis of RSV infection was mainly based on RT-PCR results $(60.7 \%)$. In the second high risk group to RSV infection, $\geq 60 \mathrm{y}$., the frequency of RSV infections was $43.3 \%$, positive results by RSV-PCR were obtained in $19.2 \%$ of 96 patients, but by RSV Ag test as much as $50 \%$ of 68 persons. The number of patients from the first group of risk was two times higher than number of elder patients. The RNA PCR results and final RSV diagnosis by age groups and number of patients are presented in figure 2 .

The significant correlations between detection of RSV infection by RT-PCR method, time of samples collection and time of onset were found: by quarter; by months and by weeks $(\mathrm{Po}=0.0000-0.0015)$. The highest percentage of positive results were in March $(30.5 \%$ of all positive), February (28.5\%), January (14.6\%), December and April (both 9\%). Only $8.4 \%$ of all positive RT-PCR samples were found in other seasons/ months. However, there were some differences depending on the particular years of testing. RSV was found 


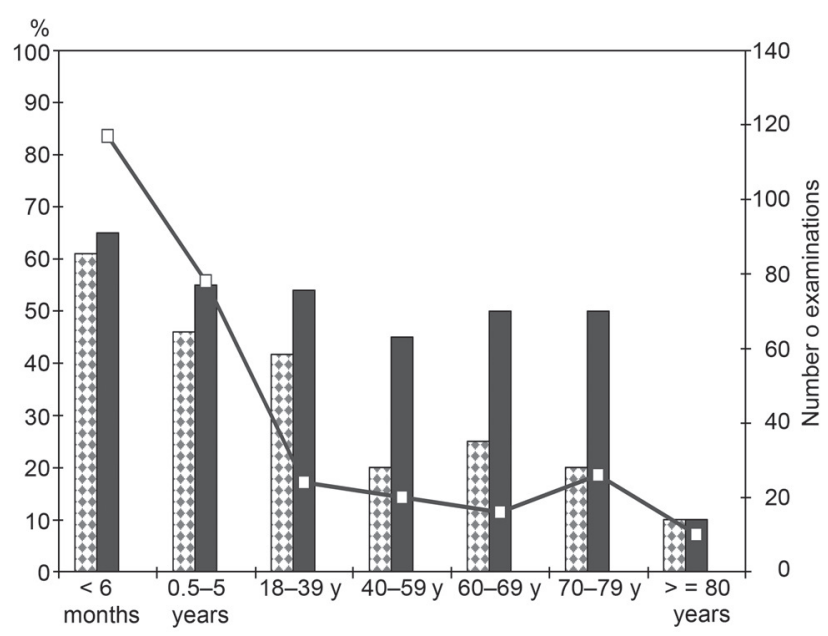

\% RSV-PCR (+) \% RSVpos diagnosis - $\square$ - number of examinations

Fig. 2. Percentage of RSV positive samples by RT-PCR method $(\mathrm{PCR}+$ ) and final RSV diagnosis (final RSV pos) by age group and number of examined patients.

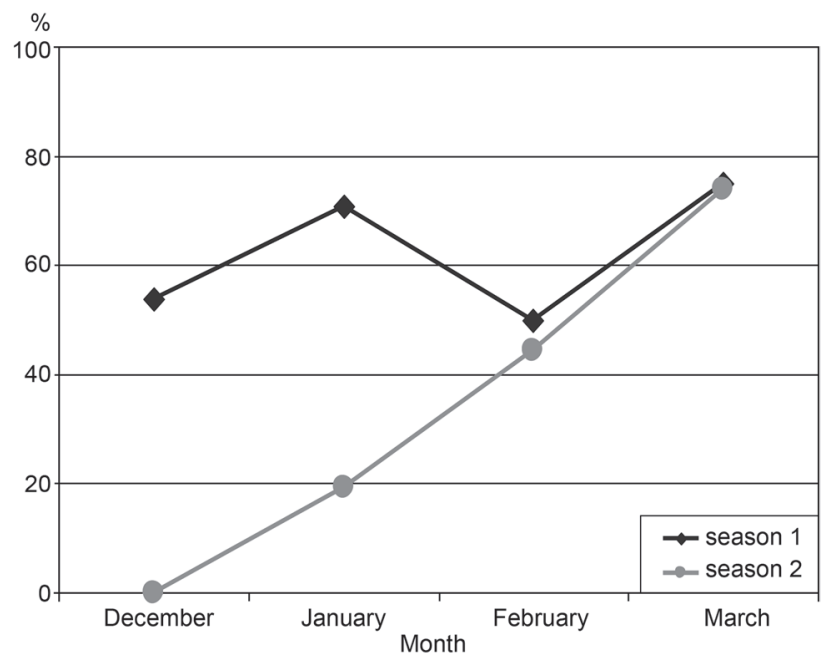

Fig. 3. Differences in frequency of RSV-positive samples (by RT-PCR) in two RSV epidemic seasons (2008-2009 and 2009-2010).

in $48.5 \%$ of swabs collected in $2008 ; 41.5 \%$ in 2009 and $50.8 \%$ of samples collected in the first three months of 2010 year. In the first season (December 2008 - March 2009) the increased percentage of positive RSV swabs was observed in December, but peak of RSV infections was in March 2009. In the second season there were no RT-PCR positive samples collected in December 2009. The percentage of positive results slowly rose during January but a high level of infections was observed in March 2010 (74\% positive samples) (Fig. 3).

\section{Discussion}

$\mathrm{RSV}$ is one of the most widespread viruses. The high risk factors of RSV infection are indicated: prematurity, especially birth at less than 35 weeks gestation; multiple birth; chronic lung disease (bronchopulmonary dysplasia, cystic fibrosis); congenital heart diseases, especially with increased pulmonary blood flow; primary immunodeficiency, including symptomatic HIV infections, immunocompromised treatment (Iwane et al., 2004; Krilov http://emedicine.medscape.co./article/971488; Belino-Studzińska and Pancer, 2008). However, the other risk factors of RSV infections are: attendance at daycare centers, crowded living conditions, living in community-dwelling, presence of school-age siblings at home and smoking habit or exposure to passive smoking (Black, 2003).

Clinical symptoms of RSV infection in general are not specific. Common RSV infections start usually as upper respiratory tract infections and during 1-2 days progress to diffuse small airway disease: cough, coryza, wheezing and rales and moderate fever $\left(38^{\circ} \mathrm{C}\right.$ and below) (Black, 2003; Krilov http://emedicine.medscape. co./article/971488) In more advanced stage cyanosis and higher fever may be observed. Reinfections of RSV occur throughout life, but they are mainly limited to upper respiratory tract infections, like common cold (7-10 days of illness) (Black, 2003; Falsey et al., 2005). Nonspecific symptoms, usually limited to upper respiratory tracts, caused that the diagnosis of RSV infection was performed only in patients of high group of risk. Moreover, problems of diagnosis of RSV infection are also connected to time of sample collection, transport and store conditions, choice of laboratory methods.

Detection of RSV genome in clinical samples from patients suspected to have RSV infections is limited only to a short period after onset (until 3-6 days), due to very fast degradation of RNA (Schultzle et al., 2008). This is a reason why we were able to found very significant correlation between the time of onset, time of sample collection and results of PCR with reverse transcriptase step method (RT-PCR), especially in examinations of children. The sensitivity of this method was very high (3-5 Units/ml). However, RT-PCR method is not able to differentiate between productive and abortive infection of RSV, because both, RNA of infectious as well as defective RSV particles, was detected.

Antigen of RSV was found in clinical samples through longer time from onset than virus RNA. Generally, the immunochromatographic tests for RSV Ag are not such sensitive as RT-PCR method is (Jaguś et al., 2010; Mahony, 2008; Mills et al., 2010). In our study, 100-1000 times differences in examinations performed with reference RSV strains were found. This test was less sensitive than RT-PCR, but no abortive infections were found.

Finally, only $23.2 \%$ among the 125 samples examined by RT-PCR and RSV Ag test were positive by both methods (52\% were positive in RT-PCR, 36\% in RSV Ag assay). Agreement of positive results obtained in 
RT-PCR and RSV Ag detection method was observed in $19 \%$ of samples from adults and $28 \%$ from children.

Detection of RSV infection among children was mainly based on positive results of RT-PCR. The predominance of positive results obtained by this method was very high in that group. In opposite, the method based on RSV antigen detection was better for identification of infections among adults, caused by this virus. It was especially visible in the first three-month period of 2010. This phenomenon might be explained by space of time between onset and sample collection. The children were hospitalized, thus nasopharyngeal swabs were collected in a few days after onset. The majority of adults were outpatients and the time of swab collection depended on scheduled of medical examinations by the specialist.

Our results indicated that the frequency of RSV infection among children and adults with chronic respiratory diseases was really high $(60.5 \%$ and $45.8 \%$, respectively), especially in epidemic seasons. High frequency of RSV infection among young children hospitalized with acute respiratory infection determined in our study, correspond to data of other authors (Ivane et al., 2004; Black, 2003; Krilov http://emedicine.medscape.co./article/971488; Olsen et al., 2010; Nair et al., 2010). RSV infection was found in $46.8 \%$ of children $<2$ y. with respiratory symptoms visiting emergency department in Edinburgh in winter season 2008-2009 (Mills, 2010). Also, RSV was the predominant etiological agent (61.3\%) among children with bronchiolitis, during a three-years study in Madrid (Calvo et al., 2010). Moreover, RSV was also recognized as an important cause of community-acquired pneumonia among hospitalized adults (Murata and Falsey, 2007). Among adult patients, $4.4 \%$ in RSV season and $1.0 \%$ in off-season were admitted with RSV infections of lower respiratory tract to the hospital in Ohio (Dowell et al., 1996). RSV was an etiological agent of pneumonia in $16.7 \%$ of 1730 patients (adults and children) in Thailand (Olsen et al., 2010). Generally, it was estimated that $3-7 \%$ of healthy elderly people and $4-10 \%$ of highrisk adults develop every year infections caused by RSV in USA (Falsey et al., 1992; Falsey et al., 2005; Hashem and Hall, 2003).

According to our analysis no difference in gender of patients with RSV infection was observed. However, other authors found that among hospitalized children frequency of boys was 2 - times higher than girls, but the difference was not significant (Black, 2003; Krilov http://emedicine.medscape.co./article/971488).

The obtained results suggest no difference in the prevalence of RSV infections in the studied groups of high risk: young children and adults with chronic respiratory tract infections. The peak of epidemic activity of RSV during 18 months of observation was the same in children and in adults. In Europe the season of RSV infections occurs in winter months, however, the peak of epidemic activity may be different. For example, in Greece the most of RSV infections were noted in February, in Italy in February during one season and in March in another season, in Croatia in January (one season) and April (another one) (Mlinaric-Galinovic et al., 2008). The season of RSV infection occurs in Poland in the winter months, usually from November to April. In both analyzed seasons the peak of epidemic activity of RSV was in March, however, there were some differences. In the first analyzed season number of RSV positive samples/patients increased slowly in November 2008 through December to one high peak in January 2009 and second peak in March 2009. In the second season (2009-2010) there were no positive RSV samples in December 2009 and suddenly the number of RSV (+) samples increased in January to the peak in March 2010. Such kind of seasonal variations were also described in Norway (Fjaerli et al., 2004) In the season 1998-99 the number of RSV positive samples increased very slowly from November to January and suddenly a very high peak of RSV (+) was in February. In another season, 1999-2000, two peaks were found: December 1999 - January 2000 and lower peak in April 2000. Results of our study show similarity rather to data obtained in Scandinavia and described by Fjaerli et al. (2004).

Conclusions. The results of our study indicate that the contribution of RSV infections to spectrum of respiratory tract diseases suspected to viral etiology in winter epidemic seasons (2008-2009 and 2009-2010) in Poland was even higher than expected. Diagnosis of RSV infection is further complicated by the concurrent influence of other common viral respiratory pathogens (especially influenza, parainfluenza, hMPV), which co-circulate with RSV during winter months. Analysis of RSV infections during subsequent seasons should be continued for better knowledge of epidemiological situation concerning the viral respiratory infections in Poland.

\section{Acknowledgments}

This study was supported by grants of Polish Ministry of Science and Education NN 404165534 (2008 - 2011) and NN 404169934 (2008-2011).

\section{Literature}

Belino-Studzińska P. and Pancer K. 2008. Respiratory syncytial virus: as an etiological agent of respiratory tract infection in children and adults (in Polish). Przegl. Epidemiol. 62: 767-75.

Black C.P. 2003. Systematic review of the biology and medical management of Respiratory syncytial virus infection. Respiratory Care 48: 209-233. 
Calvo C., F. Pozo, M.L. Garcia-Garcia, M. Sanchez, M. LopezValero, P. Pérez-Breña and I. Casas. 2010. Detection of new respiratory viruses in hospitalized infants with bronchiolitis: a three-year prospective study. Acta Paediatr. 99: 883-887.

Dowell S.F., L.J. Anderson, H.E. Jr Gary, D.D. Erdman, J.F. Plouffe, T.M. Jr File, B.J. Marston and R.F. Breiman. 1996. Respiratory syncytial virus is an important cause of community-acquired lower respiratory infection among hospitalized adults. J. Infect. Dis. 174: 456-462.

Falsey A.R., P.A. Hennessey, M.A. Formica, M.S.C. Cox and E.E. Walsh. 2005. Respiratory syncytial virus infection in elderly and high-risk adults. N. Engl. J. Med. 352: 1749-1759.

Falsey A.R., J.J. Treanor, R.F. Betts and E.E. Walsh. 1992. Viral respiratory infections in the institutionalized elderly: clinical and epidemiological findings. J. Am. Geriatr. Soc. 40: 115-119.

Fjaerli H.O., T. Farstad and D. Bratlid. 2004. Hospitalizations for Respiratory syncytial virus bronchiolitis in Akershus, Norway, 1993-2000: a population-based retrospective study. BMC Pediatric 4: 25-31.

Hashem M. and C.B. Hall. 2003. Respiratory syncytial virus in healthy adults: the cost of cold. J. Clin. Virol. 27: 14-21.

Iwane M.K., K.M. Edwards, P.G. Szilagyi, S.G. Humiston, R. Barth, T. McInerny, L. Shone and B. Schwartz. 2004. Population-based surveillance for hospitalizations associated with Respiratory syncytial virus, Influenza virus, and Parainfluenza viruses among young children. Pediatrics 113: 1758-1764 updated 2010: http://www.pediatrics.org/cgi/content/full/113/6/1758.

Jaguś P., J. Chorostowska-Wynimko and A. Roży. 2010. Diagnostics of some viral infections of respiratory tract (in Polish). Pneumonol. Alergol. Pol. 78: 47-53.

Krilov L.R. Respiratory Syncytial Virus (RSV) infection. eMedicine Pediatrics. http://emedicine.medscape.com/article/971488.

Lamb R.A. and G.D. Parks. 2007. Paramyxoviridae. The Viruses and their Replication. pp. 1449-1496 In: Knipe D.M, Howley P.M (eds.) Fields of virology Lippincott Williams\& Wilkins, Wolters Kluwer Business.

Łuczak G., E. Kozielska, J. Tyl, A. Borkowska, A. Galińska, W. Radys and Z. Bohdan. 2003. Role of Respiratory syncytial virus in respiratory tract infections pathogenesis in infants and small children. Med. Sci. Monit. 9: 44-47.

Mahony J.B. 2008. Detection of respiratory viruses by molecular methods. Clin. Microbiol. Rev. 21: 716-747

Mills J.M., J. Harper, D. Broomfield and K.E. Templeton. 2010. Rapid testing for Respiratory syncytial virus in a pediatric emergency department: benefits for infection control and bed management. J. Hosp. Infect. doi:10.1016/j.jhin.2010.11.019
Mlinaric-Galinovic G., R.C. Wellver, T. Vilibic-Cavlek, S. LjubinSternak, V. Drazenovic, I. Galinovic and V. Tomic. 2008. The biennial cycle of Respiratory syncytial virus outbreaks in Croatia. Virology Journal. 5: 18-23.

Murata Y. and A.R. Falsey. 2007. Respiratory syncytial virus infection in adults. Antivir. Ther. 12: 659-670.

Nair H., D.J. Nokes, B.D. Gessner, M. Dherani, S.A. Madhi, R.J. Singleton, K.L. O'Brien, A. Roca, P.F. Wright, N. Bruce and others. 2010. Global burden of acute lower respiratory infections due to Respiratory syncytial virus in young children: a systematic review and meta-analysis. Lancet 375: 1545-1555.

Olsen S.J., S. Thamthitiwat, S. Chandra, M. Chittaganpitch, A.M. Fry, J.M. Simmerman, H.C. Baggett, T.C. Peret, D. Erdman, R. Benson and others. 2010. Incidence of respiratory pathogens in persons hospitalized with pneumonia in two provinces in Thailand. Epidemiol. Infect. 21: 1-12.

Pancer K., A. Panasik, W. Gut, B. Lipka, D. Puchta, B. MilewskaBobula, D. Dzierżanowska and B. Litwińska. 2010a. Infections caused by RSV - problems of diagnostic based on serological examinations. pp. 115-122. In: M. Polz-Dacewicz (ed.) Viral Infectiondiagnostics, prevention and control. The role of viral infection in public health. Uniwersytet Medyczny w Lublinie, Polskie Towarzystwo Wirusologiczne, DA Studio

Pancer K., A. Panasik, A. Makówka, P. Belino-Studzińska, W. Gut, D. Puchta, D. Dzierżanowska and B. Litwińska. 2010b. The influence of preanalytical factors on detection of RNA viruses by reverse transcription - polymerase chain reaction (RT-PCR). pp. 105-113. In: M. Polz-Dacewicz (ed.) Viral Infection-diagnostics, prevention and control. The role of viral infection in public health. Uniwersytet Medyczny w Lublinie, Polskie Towarzystwo Wirusologiczne, DA Studio.

Roca A., M.P. Loscertales, L. Quintó, P. Pérez-Breña, N. Vaz, P.L. Alonso and J.C. Saiz. 2001. Genetic variability among group A and B Respiratory syncytial viruses in Mozambique: identification of a new cluster of group B isolates. J. Gen. Virol. 82: 103-11.

Schutzle H., J. Weigl, W. Puppe, J. Forster and R. Berner. 2008. Diagnostic performance of a rapid antigen test for RSV in comparison with a 19-valent multiplex RT-PCR ELISA in children with acute respiratory tract infections. Eur. J. Pediatr. 167: 745-749.

Sullender W.M. 2000. Respiratory syncytial virus genetic and antigenic diversity. Clin. Microbiol. Rew. 13: 1-15.

Światły A. 2001. Acute bronchitis (in Polish). Przew Lek. 4: 6, 89-91. Tranda I., J. Wilczyński, M. Wróblewska-Kałużewska and E. Torbicka. 2000. Epidemiology of respiratory tract acute viral infections in children during first two years (in Polish). Ped. Pol. 75: 619-623. 